\title{
Development and testing of natural draught desert cooler
}

\author{
Ashok Kumar Sharma \\ Department of Mech. Engineering \\ Yagyavalkya Institute of Technology \\ Jaipur, India
}

\author{
Pawan Bishnoi \\ Department of Mech. Engineering \\ Yagyavalkya Institute of Technology \\ Jaipur, India
}

\begin{abstract}
To save the environment it is primarily required to save electricity. Since, generation of electricity add pollutants to the environment. The developed desert cooler which is described in this paper uses naturally blowing air to provide the cooling effect. It allows air to enter inside the cooler from four sides while allows outgoing of air only through a passage in bottom. Thus naturally blown air is circulated inside the room through desert cooler, which requires no electricity to blow the air as in conventional desert coolers. The paper describes the methods of designing and manufacturing of this desert cooler. A test setup is presented which was prepared to test the effectiveness of this developed cooler. The methodology of testing and test data are also presented. The results show that this device is effective in providing cooling without using electricity for blowing the air.
\end{abstract}

Keywords: Desert cooler, natural draught, cellulose cooler pads, air retainers

\section{INTRODUCTION}

In the recent decades the demand for air cooling has increased due to high dry bulb temperature and low humidity of air in Rajasthan, specially in Jaisalmer and Barmer districts where during summar dry bulb temperature of air reached up to $50^{\circ} \mathrm{C}$ while relative humidity is below $48 \%$. This climate is suitable for evaporative cooling. In a conventional air cooler a motor is used to drive the fan and to pump water for cooling and humidification of air. In this paper a modified cooler is presented with low electric energy consumption using natural draft system for air flow through the cooler. The major advantage of this equipment is to eliminate the fan used for air flow through cooler and thus reducing the electricity requirement.

\section{LITERATURE REVIEW}

Literature review reveals that lot of efforts have been made to make the desert cooler energy efficient as Faleh Al-Sulaiman [1] used various fibers like date palm fibers, jute and luffa for wetted cooler pads and evaluated the performance resulted jute has maximum cooling efficiency. Kothare and Borker [2] presented a "Modified Desert Cooler (MDC)" which cools the air more efficiently than the conventional desert cooler as well as provide cold-pure water for drinking purpose. It also decreased moisture content of the air coming through desert cooler upto some extent. Poonia M.P. et al. [3] have developed a cooler cum refrigerator which provides air cooling, cold drinking water and stores the vegetables and medicines without affecting the performance of desert cooler. This is energy saver useful equipment.

Khond [4] has investigated a performance of Desert Cooler using four different pad materials i.e. stainless steel wire mesh, coconut coir, khus and wood wool. They observed that minimum water consumption was in stainless steel wire mesh and maximum cooling efficiency was found using wood wool pads.

Many researchers have presented analytical models and methods to calculate and optimized the performance of desert cooler. Erens and Dreyer [5] presented three analytical models and optimized the shape of the cooler. Guo and Zhao [6] numerically analyzed the thermal performance of an indirect evaporative air cooler. Ren and Yang [7] developed an analytical model for the coupled heat and mass transfer processes under real operating conditions with parallel counter-flow configurations. ShariatyNiassar \& Gilani [8] have applied CFD technique to examine the different types of indirect evaporative coolers. Navon and Arkin [9] were focused on providing thermal comfort using directindirect evaporative cooler. In their studies Amr Sayed et al. [10] have considered housing problems and indoor environment which attributed to thermal comfort.

\section{DESIGN AND DEVEOPMENT OF IMPROVED DESERT COOLER}

As shown in figures $1 \& 3$ a modified cooler has been manufactured which has cooler grills on four sides of the cooler. The grills are provided with the arrangement to receive maximum naturally blowing air. The outlet of air from the cooler is facilitated at the bottom along with water tank as shown in figure $1 \& 4$ which will convey that air to test chamber / room where cooling is required. The cooler grills are provided with cellulose pads. Inside the cooler the pads are facilitated with baffles as shown in figures $2 \& 4$ which allow naturally blowing air inside the cooler and prevent exit from grills to direct air to pass through conical receiver. Since this cooler uses only naturally blowing air for cooling purpose therefore, no blower is required. Electric power will be used only for 
International Journal of Science and Engineering Applications (IJSEA)

Volume 2 Issue 1, 2013, ISSN - 2319-7560 (online)

circulating water from water tank to grills with the help of electric pump.

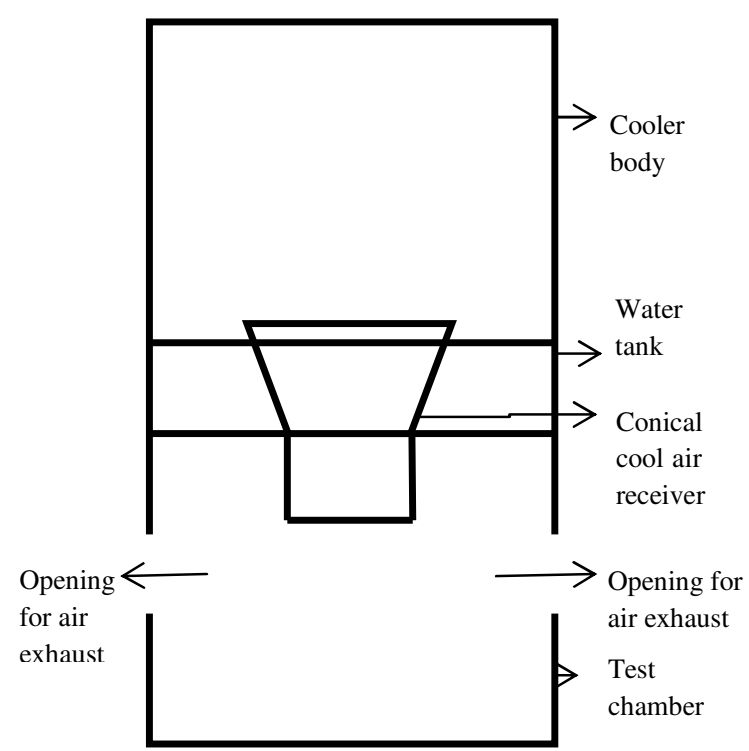

Figure 1 Arrangement of cooler body and test chamber

This modified cooler can be placed on the roof of any building to receive maximum naturally blowing air 24 hours. The air is than, can be circulated to the rooms where cooling required through duct after passed through the cooler.

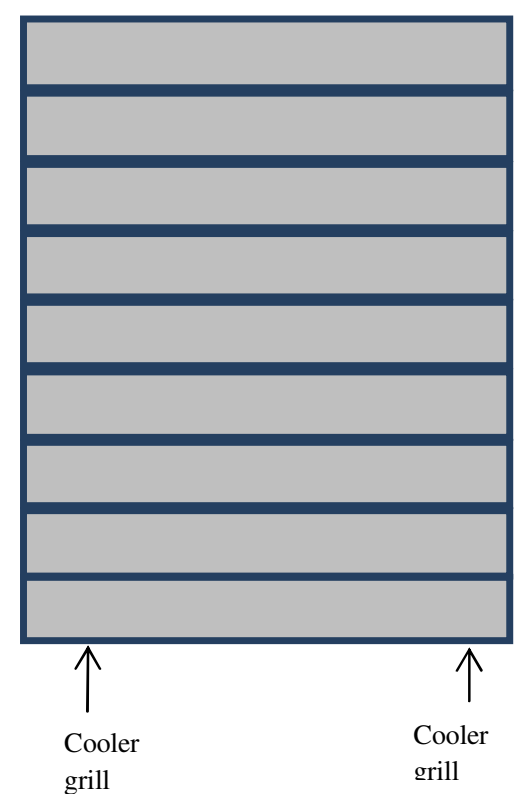

Figure 2 Arrangement of baffles on cooler grill

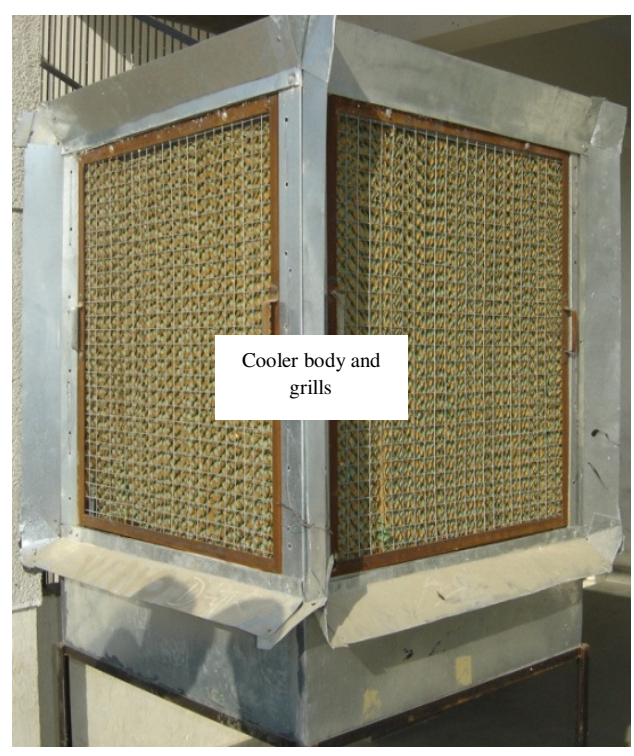

Figure 3 Cooler body and cellulose cooler pads

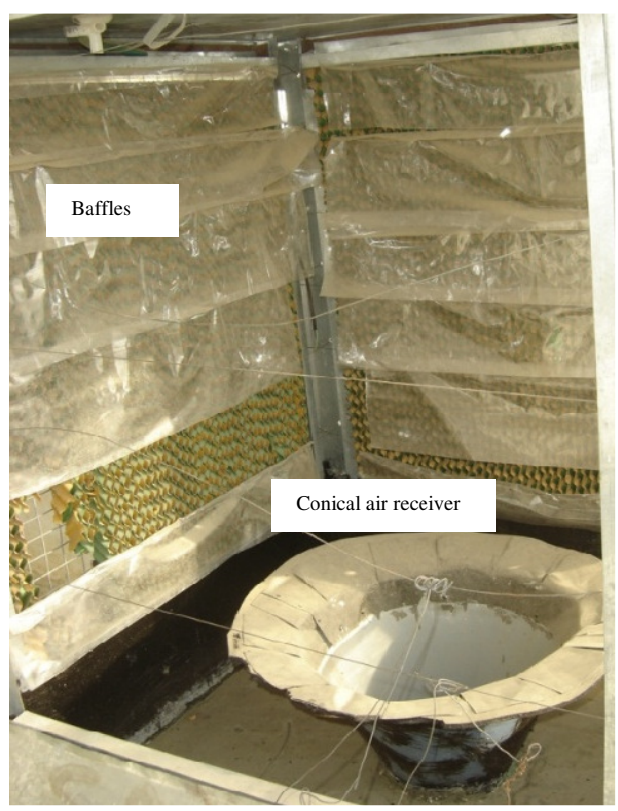

Figure 4 Arrangement of conical cool air receiver and baffles on cooler grill 


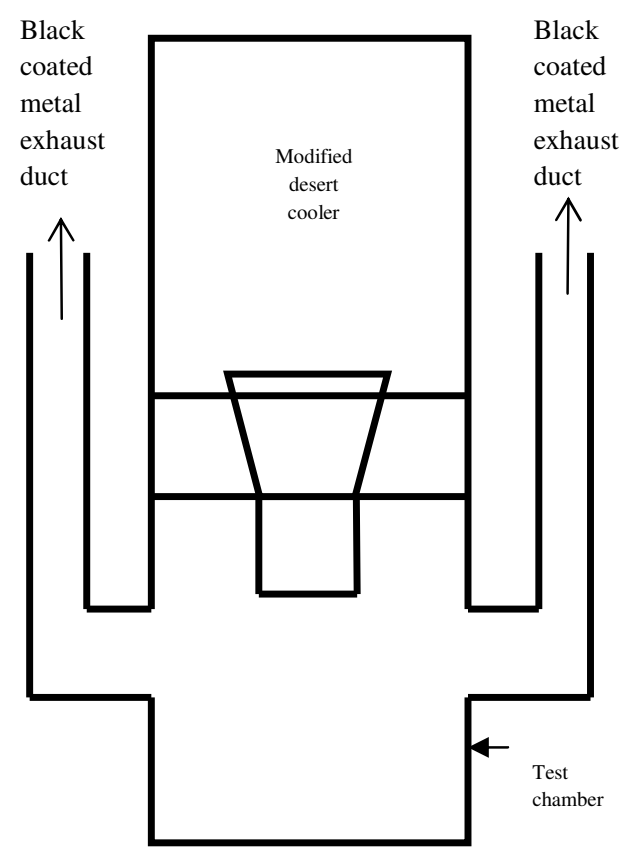

Figure 5 Arrangement of black coated metal exhaust ducts in test setup II

\section{TEST AND RESULTS}

Arrangements for testing of modified desert cooler are provided in figures $1 \& 5$. A test chamber of size $930 \mathrm{~mm}$ x $980 \mathrm{~mm} \mathrm{x}$ $980 \mathrm{~mm}$ was prepared under the cooler to test the cooling effect of the cooler. This test chamber was insulated and a thermometer was inserted in it through the insulated wall to measure the temperature of the test chamber. The testing arrangements as shown in figures are different in one aspect is that exhaust of air from test chamber as in figure 1 passes through plain openings on two sides, whereas exhaust air as in figure 5 passes through exhaust ducts provided on two sides. The later provides effective exhaust of air from test chamber creating naturally induced draught after heating of exhaust ducts by sunrays. The design of exhaust duct is provided in figure 6 . The test observations / results are tabulated in the tables $1 \& 2$ and also presented in figure $7 \& 8$.

\section{CONCLUSIONS}

On analyzing the observations in table $1 \& 2$ and figures $7 \& 8$ it is concluded that -

(a) Naturally draught cooler is effective equipment in providing cooling effect without using blower (table 1 \& figure 7).

(b) The device is comparatively more effective with black color coated exhaust ducts (table $2 \&$ figure 8 ) as it provides effective draught to exhaust air from the room / test chamber.

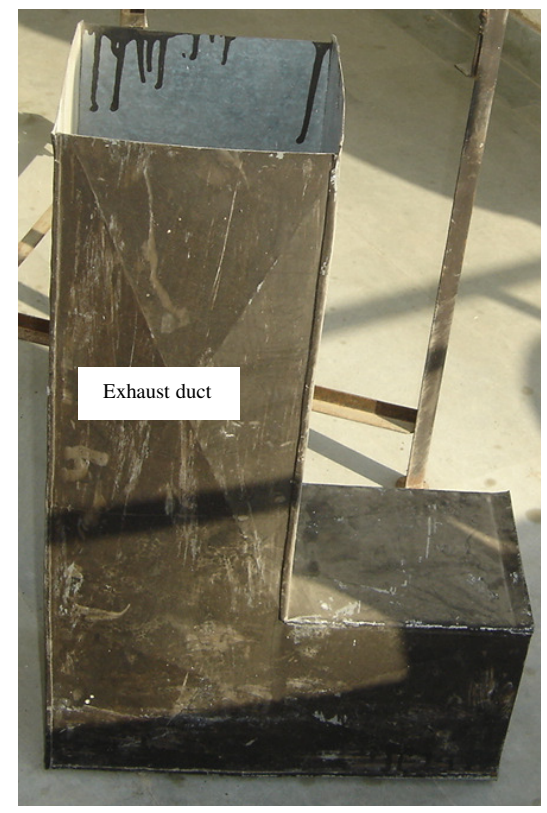

Figure 6 Black color coated metal exhaust duct

(c) Since, there is no blower in the modified desert cooler therefore, no electricity is required. Hence, the equipment is economical in operation and environment friendly.

(d) The cooler is suitable for most of the types of buildings.

Table 1 Cooling effect of modified desert cooler

\begin{tabular}{|c|c|c|c|}
\hline S.No. & $\begin{array}{c}\text { Time } \\
(\mathbf{m i n} .)\end{array}$ & $\begin{array}{c}\text { Water } \\
\text { temperature } \\
\left({ }^{\mathbf{C}} \mathbf{C}\right)\end{array}$ & $\begin{array}{c}\text { Test chamber } \\
\text { temperature } \\
\left({ }^{\mathbf{}} \mathbf{C}\right)\end{array}$ \\
\hline 1. & 0 & 45 & 38.2 \\
\hline 2. & 20 & 43.9 & 37.5 \\
\hline 3. & 40 & 42.8 & 36.9 \\
\hline 4. & 60 & 41.9 & 36.3 \\
\hline 5. & 80 & 40.8 & 35.6 \\
\hline 6. & 100 & 39.8 & 35.0 \\
\hline 7. & 120 & 38.7 & 34.4 \\
\hline 8. & 140 & 37.8 & 33.9 \\
\hline 9. & 160 & 36.8 & 33.4 \\
\hline 10. & 180 & 35.9 & 32.9 \\
\hline 11. & 200 & 35.0 & 32.4 \\
\hline 12. & 220 & 34.1 & 32.0 \\
\hline 13. & 240 & 33.3 & 31.5 \\
\hline 14. & 260 & 32.4 & 31.1 \\
\hline 15. & 280 & 31.5 & 30.7 \\
\hline 16. & 300 & 30.7 & 30.3 \\
\hline
\end{tabular}


International Journal of Science and Engineering Applications (IJSEA)

Volume 2 Issue 1, 2013, ISSN - 2319-7560 (online)

Table 2 Cooling effect of modified desert cooler with black color coated exhaust ducts.

\begin{tabular}{|c|c|c|c|}
\hline S.No. & $\begin{array}{c}\text { Time } \\
(\mathbf{m i n} .)\end{array}$ & $\begin{array}{c}\text { Water } \\
\text { temperature } \\
\left({ }^{\mathbf{C}} \mathbf{)}\right.\end{array}$ & $\begin{array}{c}\text { Test chamber } \\
\text { temperature } \\
\left({ }^{\mathbf{}} \mathbf{C}\right)\end{array}$ \\
\hline 1. & 0 & 45.5 & 38.4 \\
\hline 2. & 20 & 44.4 & 37.7 \\
\hline 3. & 40 & 43.1 & 36.9 \\
\hline 4. & 60 & 41.9 & 36.1 \\
\hline 5. & 80 & 40.7 & 35.3 \\
\hline 6. & 100 & 39.5 & 34.5 \\
\hline 7. & 120 & 38.4 & 33.8 \\
\hline 8. & 140 & 37.2 & 33.1 \\
\hline 9. & 160 & 36.0 & 32.4 \\
\hline 10. & 180 & 34.8 & 31.7 \\
\hline 11. & 200 & 33.7 & 31.1 \\
\hline 12. & 220 & 32.5 & 30.5 \\
\hline 13. & 240 & 31.5 & 29.9 \\
\hline 14. & 260 & 30.6 & 29.3 \\
\hline 15. & 280 & 29.6 & 28.7 \\
\hline 16. & 300 & 28.7 & 28.1 \\
\hline & & & \\
\hline
\end{tabular}

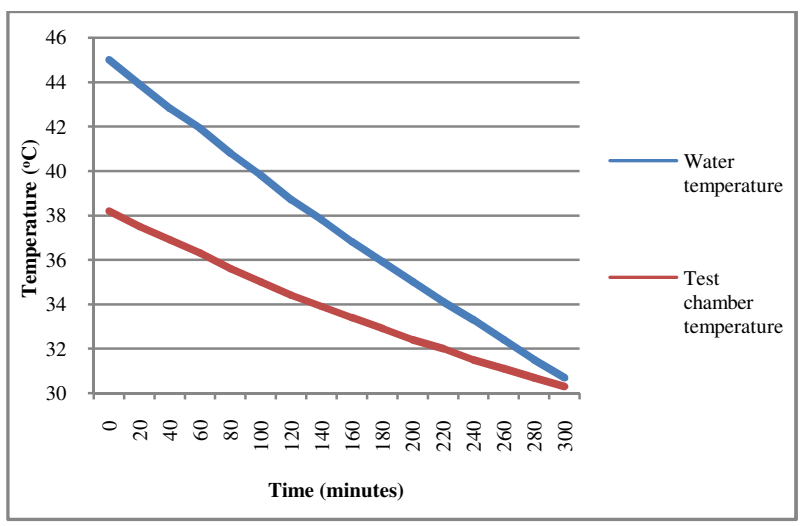

Figure 7 Cooling effect of modified desert cooler

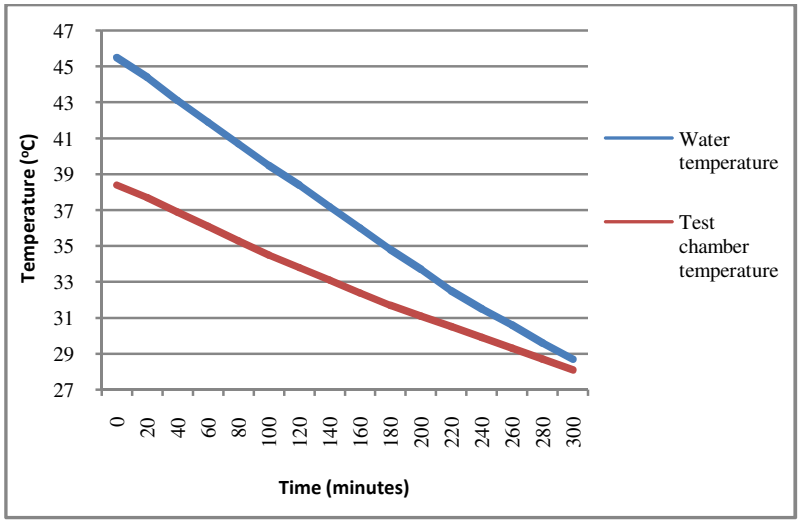

Figure 8 Cooling effect of modified desert cooler with black color coated exhaust ducts.

\section{REFERENCES}

[1] Al-Sulaiman, F. 2002. Evaluation of the performance of local fibers in evaporative cooling. Energy Conversion and Management. 43(16), 2267-2273.

[2] Kothare, C. B. and Borkar, N. B. 2011. Modified desert cooler (MDC). International Journal of Engineering and Technology. 3 (2), 166-172.

[3] Poonia M.P., Bhardwaj A., Upender P., Jethoo A.S. 2011. Design and development of energy efficient multi-utility desert cooler. Universal Journal of Environmental Research and Technology. 1, 39-44.

[4] Khond, V. W. 2011. Experimental investigation of desert cooler performance using four different cooling pad materials. American Journal of Scientific and Industrial Research. 418-421.

[5] Erens, P. J. and Dreyer, A. A. 1993. Modeling of indirect evaporative coolers. International Journal of Heat and Mass Transfer. 36 (1), 17-26.

[6] Guo, X. C. and Zhao, T. S. 1998. A parametric study of an indirect evaporative air cooler. Heat and Mass Transfer. 25 (2), 217-226.

[7] Ren, C. and Yang, H. 2006. An analytical model for the heat and mass transfer processes in indirect evaporative cooling with parallel / counter flow configurations. International Journal of Heat and Mass Transfer. 49, 617627.

[8] Gilani, N. and Shariaty-Niassar, M. 2009. An investigation of indirect evaporative coolers (IEC) with respect to thermal comfort criteria. Iranian Journal of Chemical Engineering. 6(2), 14-28.

[9] Navon, R. and Arkin, H. 1994. Feasibility of direct indirect evaporative cooling for residences, based on studies with a desert cooler. Building and Environment, 29 (3), 393-399.

[10] Amr Sayed, H., Hiroshi, Y., Abdelsamei Eid, M. and Magdy, M. R. 2012. Indoor natural ventilation using evaporating cooling strategies in the Egyptian housing: A review and new approach. International Journal of Engineering and Technology. 4(3), 229-233. 